\title{
Sustainability as part of corporate identity in conditions of globalization
}

\author{
Veronika Paurova ${ }^{1,}$, Darina Chlebikova $^{2}$ \\ ${ }^{1}$ University of Zilina, Faculty of Operation and Economics of Transport and Communications, \\ Department of Economics, Univerzitna 1, 01026 Zilina, Slovak Republic \\ ${ }^{2}$ University of Zilina, Faculty of Operation and Economics of Transport and Communications, \\ Department of Economics, Univerzitna 1, 01026 Zilina, Slovak Republic
}

\begin{abstract}
Sustainable development is characterised as condition in which the elements of the global ecosystem are balanced. All organizations and individuals who form the global community should try to achieve this state. Sustainable development has become one of the most important global challenges in the 21 st century. It is a long-term process that affects the environment, the economy and society at local or global level. It is essential to observe sustainability principles for companies in globalizing markets. Corporate identity is a process of identification of company. The elements of corporate identity are interconnected, and their creation should have a clear concept and strategy. The main goal is to create an original identity that distinguishes the business from the competition. If a business wants to be competitive, it must respect and apply the principles of the global environment, for example sustainable development. The purpose of article is to point out the background of sustainable development and corporate identity and the importance of these two areas for businesses in the context of globalization. Research is based on secondary findings from Sustainable Society Foundation and we used comparative analysis. We found out that some indicators in terms of sustainability needs to be improved.
\end{abstract}

\section{Introduction}

Marketing is one of the most constantly changing and developing issues currently [1]. Already in the early 1970 s, society began to realize more deeply that natural resources are exhaustible, and as their consumption increases in any respect, the question arises as to whether uncontrollable growth can be sustained in the long term. It is not only the growth of the business as an economic entity, but also the unsustainable growth of the population of some countries, the economy, the growth of consumption, or the pollution of nature. Sustainable advancement is crucial to worldwide [2]. Entrepreneurs should do the right things, such as: acting seriously with customers and partners, caring for their workers, fostering good relationships and, finally, protecting the environment. Market environment is more and more globalized [3]. In today's global world, it is essential for businesses to behave responsibly. Changing market conditions lead managers to making several decisions

\footnotetext{
*Corresponding author: veronika.paurova@fpedas.uniza.sk
} 
that can significantly affect the competitive fight and market position of the company. Corporate identity is a way, how can company differentiate itself from competitors and identify themselves. Corporate identity is a factor that has a significant impact on the company's competitive potential. Corporate identity is for companies important, because it is generally recognised at present as a useful strategic tool and also because a competitive advantage can be achieved through it [4]. Regarding the corporate identity, it is important to point out corporate social responsibility (CSR) that is as an essential aspect of corporate identity. Corporate responsibility means setting business processes in line with sustainability, with respect to the environment and society. The concept of socially responsible business should be part of the strategic planning of any company that is or strives to be successful. The concept of CSR is also referred corporate sustainability. Corporate sustainability areas include strategy and management, supply chain and production, climate, environment and energy, employees, human rights community and society. Corporate responsibility is manifested in three main areas, namely economic, social and environmental. In the economic field, it should be the monitoring and improvement of processes by which the company contributes to economic development and the effort to minimize any negative consequences resulting from this activity. In the social field, it should be to monitor and minimize the negative consequences for the entire social system and society. In the environmental field, it should be monitoring and reducing the negative impacts of business on the environment, for example production of ecological products, waste recycling, protection of natural resources, use of alternative energy sources and others. The paper is divided into two basic parts. The first part is focused on the identification of theoretical background related to corporate identity and sustainable development. The second part consists of secondary analysis of Sustainable Society Index (SSI) of The Visegrad Group (V4).

\subsection{Corporate identity}

Corporate identity is a collective personification of the company derived from its philosophy, history, strategy, culture, reputation, and management style and employee behaviour. Literature offers many definitions of corporate identity. Corporate identity is an effort for external distinctiveness, uniqueness and individuality that reflect in components such as design, corporate behaviour, culture, product and communication. Corporate identity is purposefully created concept that embraces the intrinsic structure, functioning and presentation of a particular company in market environment, expressing its originality, unmistakability and specificity compared to other businesses. According to Paliderova [5] each company has its own unique identity. Corporate identity is the strongest useful asset that brings intangible value to a company [6]. The corporate identity is process of create a clear presentation of the company in the process of internal and external communication. Corporate identity is process of building a positive image, shaping a positive corporate culture, identifying employees with the company, aligning of the internal and the external image of the company, creating a sense of confidence and trust towards the company. Authors have different opinions about components of corporate identity. Melewar and Karaosmanoglu [4] state seven components of corporate identity: corporate communication, corporate culture, corporate design, corporate behaviour, industrial identity, organisational structure and corporate strategy. It is important for companies to improving each components of corporate identity. Corporate communication is important considering all interest groups - employees, customers, shareholders and others, because it can lead to increased customer loyalty, better market position and long-term relationship with stakeholders [7]. Corporate identity is important for companies in terms of their social status. At present, almost all business entities offer the same product at the same price and 
under the similarly technological conditions. Corporate identity can help businesses succeed. Corporate identity has become an important part of the organisation's management and it is an important source of competitiveness. All components of corporate identity including corporate communication, corporate behaviour, corporate culture, corporate design, corporate strategy and corporate personality have a significant impact on the company's image [8]. Corporate image have the potential to affect customer loyalty to the company in a competitive environment, because the degree of customer loyalty is higher when the perception of corporate reputation and the corporate image is favourable.

\subsection{Sustainability development}

Regarding sustainable development, it has emerged as the latest development catchphrase. Many authors believe that science and technology must play a more central role in sustainable development, but there are still few systematic studies on how to create institutions that effectively use science and technology for sustainability. Sustainable development is a targeted, long-term, complex and synergistic process, affecting conditions and all aspects of life (cultural, social, economic, environmental and institutional), at all levels (local, regional, global) and towards such functional a model of a community (local and regional community, country, international community) that satisfies people's needs and interests while eliminating or significantly reducing interventions threatening, damaging or destroying living conditions and forms; peace, rationally uses its resources and protects cultural and natural heritage.

The Sustainable Development Goals include:

1. No Poverty

2. Zero Hunger

3. Good Health and Well-being,

4. Quality Education,

5. Gender Equality

6. Clean Water and Sanitation

7. Affordable and Clean Energy

8. Decent Work and Economic Growth

9. Industry, Innovation, and Infrastructure

10. Reducing Inequality

11. Sustainable Cities and Communities

12. Responsible Consumption and Production

13. Climate Action

14. Life Below Water

15. Life On Land

16. Peace, Justice, and Strong Institutions

17. Partnerships for the Goals

(https://www.globalgoals.org/)

Sustainability is not anticipated as a definite result but rather as a direction [9]. According to Kiselakova et al. [10] sustainable development is closely related to business performance and management. The basic strategic objectives of each organization include long-term growth and sustainability. Ukko et al. [11] point to three dimensions of sustainable development, namely the economic, social and environmental dimensions. Opon \& Henry [12] state that sustainable development is characterized as a development that meets the needs of the present without compromising the ability of the future generation to meet their own needs. They further state that this is an envisaged interconnection of three basic pillars: the environment, the economy and society. The 21 stcentury definition of sustainability refers to the need to develop the sustainable models 
necessary for both the human race and planet Earth to survive [13]. Each country is required to incorporate the principles of sustainable development into its programs and policy policies and strive to achieve the objectives of sustainable development. These targets address poverty and health, but also new areas such as climate change, economic inequality, innovation, sustainable consumption, peace and justice [14]. Sustainable development has evolved into a concept, consistently demonstrating its potential to reshape the manufacturing enterprises. For manufacturing company, the concept of Sustainable development is about making manufacturing systems and practices responsive to the demands of three dimensions of sustainability - economic or profit, ecological or planet, and social or people [15].

\section{Methods}

Each company is located in a certain environment, which can be understood from the perspective of business diagnostics as a certain temporal and spatial reality and a summary of elements of the environment with which the company is related and related. The aim of this part is to provide a review of level of sustainability in the Visegrad Group (V4) with emphasis on Economic Wellbeing. This research is based on secondary findings from Sustainable Society Foundation. We used comparative analysis. Our final statements are based on the outcomes of Sustainable Society Foundation. We compared Sustainable Society Index (SSI) of V4 countries in the methodological part. This indicator defines sustainable development according to the United Nations Organisation (UNO). Indicators of this index include ecological, environmental and human well-being. According to the index creators, it is necessary for sustainable development to integrate these three indicators into the index and try to fulfil them together. Sustainable Society Index (SSI) is transparent tool showing at a glance the level of sustainability of a country. The SSI integrates Human Wellbeing and Environmental Wellbeing. This is the way to look at development in a sustainable world. Economic Wellbeing is integrated as a condition to achieve Human and Environmental Wellbeing. Figure 1 shows Sustainable Society Index (SSI) of the Visegrad Group (V4). The spiderweb shows the score of each of the 21 indicators of countries on a scale of $1-10(10=$ sustainable, $1=$ not sustainable $)$.

\section{Indicators include:}

1. Sufficient Food - number of undernourished people in $\%$ of total population

2. Sufficient to Drink - number of people in $\%$ of total population, with sustainable access to an improved water source

3. Safe Sanitation - number of people in $\%$ of total population, with sustainable access to improved sanitation

4. Education - Gross enrolment ratio for primary, secondary \& tertiary education (combined)

5. Healthy Life - Life expectancy at birth in number of healthy life years

6. Gender Equality - Gender Gap Index

7. Income Distribution - Ratio of income of the richest $10 \%$ to the poorest $10 \%$ people in a country

8. Population Growth - 5-years change in total population size (\% of total population)

9. Good Governance - Sum of the six Worldwide Governance Indicators

10. Biodiversity - forest area

11. Renewable Water Resources - Annual water withdrawals (m3 per capita) as \% of renewable water resources

12. Consumption - Ecological Footprint minus Carbon Footprint

13. Energy Use - Energy use (tonnes of oil equivalent per capita) 
14. Energy Savings - Change in Energy use over 4 years $(\%)$

15. Greenhouse Gases - $\mathrm{CO}_{2}$ emissions per person per year

16. Renewable Energy - Consumption of renewable energy as \% of total energy consumption

17. Organic Farming - Area for Organic Farming in \% of total agricultural area of a country

18. Genuine Savings - Genuine Savings (Adjusted Net Savings) as \% of Gross National Income

19. GDP - Gross Domestic Product per capita

20. Employment - Number of unemployed people in $\%$ of total labour force

21. Public Debt - The level of Public Debt of a country in \% of GDP

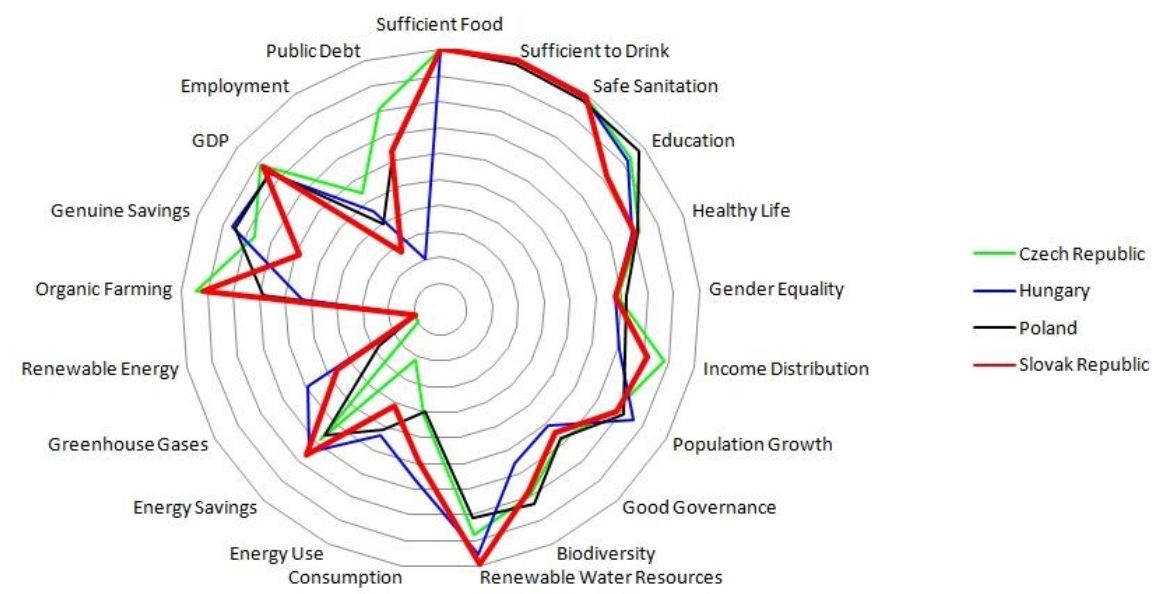

Fig. 1. Sustainable society index (SSI) of the Visegrad group (V4)

Source: own processing based on http://www.ssfindex.com

We can see in the figure 1 that the individual levels of sustainability of individual countries are approximately the same. Looking at individual indicators of individual countries and its comparison, we can see differences in the indicator Education, where the Slovak Republic has the lowest value compared to other V4 countries. Income Distribution is the highest in the Czech Republic and the lowest in Hungary. Biodiversity has the highest value in Poland and the lowest in Hungary. The difference can also be seen in the Greenhouse Gases indicator, where Hungary and Slovakia have a higher value and lower Czech and Poland.

As the paper focuses on sustainability in the economic context, the following figure shows the differences between countries within the Economic Welfare category. This category includes GDP, Employment and Public Debt. 


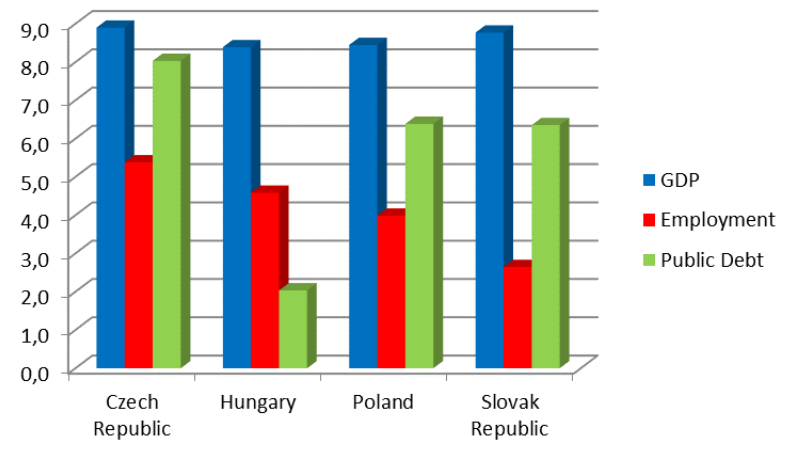

Fig. 2. Economic Welfare of the Visegrad group (V4)

Source: own processing based on http://www.ssfindex.com

The figure shows that in terms of GDP indicator, in all 4 countries of the Visegrad Group its value is approximately the same. The Employment indicator has the highest value in the Czech Republic and the lowest in the Slovak Republic. The Public Debt indicator has the highest value in the Czech Republic and the lowest in Hungary.

\section{Results and Discussion}

By comparing individual data, we can say that, in terms of sustainability, some indicators, such as Greenhouse Gases, Renewable Energy, Employment needs to be improved. Subsequent generations will feel the consequences of what will be done or not in the field of sustainability. According to corporate identity and issue of sustainable development, Chen [16] points out to green organizational identity. He defines it as a scheme about environmental management and protection that members collectively construct to provide meaning to their behaviours. Song et al. [17] state that green organizational identity plays an important role in firms. Green marketing is a potential source of competitive advantage [18]. For companies can be source of a long-term sustainable competitive advantage also for example brand [19]. The brand itself is one of the most important components of corporate intangible wealth [20]. However, the implementation of sustainable development is often not easy at times. Jaramillo, et al. [21] investigated and analysed the obstacles faced by SMEs in implementing sustainable development, such as lack of resources, high initial capital costs to implement sustainability measures and lack of expertise. The Organization for Economic Co-operation and Development (OECD) plays an important role in addressing sustainable development issues worldwide. One of the main objectives of the OECD is to achieve sustainable economic growth in member countries in relation to global sustainable growth and international commitments. Corporate identities are generally installed with different dimensions and intentions. Global change is related to sustainability, which enables recognition of corporate identities in the business world. It is important to analyse the current impact of sustainable development mechanisms on the economy [22]. Saving resources and the environment in terms of sustainable management should be part of the corporate culture and the continuous improvement of the efficiency of the entire process chain from supplier to end customer. Nielsen \& Johansen [23] states that companies have to act in new ways in order to deal with pressures brought on by a number of different issues (for example climate change, sustainability, financial scandals and crisis etc.). CSR is important, because it may be argued that it is also becoming an aspect of corporate identity management and communication [24]. Clearly, in addition to the basic 
elements of corporate identity, we can identify sustainable development as part of corporate identity.

\section{Conclusion}

Sustainability of a company means its involvement in the social responsibility of protecting natural resources and maintaining the quality of the environment, which significantly helps to preserve and create the conditions for the lives of future generations. Measures that conserve natural resources and protect the environment today should be a natural part of any corporate identity in terms of sustainable behaviour. The main objective of sustainability of companies is to take responsibility for their behaviour towards people and the environment, which should also be linked to their efforts to achieve the highest possible sustainable business. Nowadays, the priorities of businesses are conditioned by CSR and in this context the principles of entrepreneurship have been formulated, which will bear the benefit of social responsibility. It is mainly the responsibility of companies for their immediate surroundings, which is also related to the effort of sustainable development.

This paper is an output of scientific project VEGA no. 1/0718/18: The impact of psychographic aspects of pricing on the marketing strategy of companies across products and markets.

\section{References}

1. A. Krizanova, J. Majerova, T. Kliestik, P. Majercak, Theoretical Aspects of Brand Building in Seafood Industry. Nase more, 60 (5-6), 105-112 (2013)

2. A.D. Meilă, Sustainable Urban Mobility in the Sharing Economy: Digital Platforms, Collaborative Governance, and Innovative Transportation. Contemporary Readings in Law and Social Justice, 10(1), 130-136 (2018)

3. J. Kliestikova, K. Janoskova, Branding with understanding: how national profile of consumer influences brand value perception. Marketing and management of innovations, 3, 149-157 (2017)

4. T.C. Melewar, E. Karaosmanoglu, Seven dimensions of corporate identity: A categorisation from the practitioners' perspectives. European Journal of Marketing, 40 (7-8), 846-869 (2006)

5. M. Paliderova, A. Bielikova and E. Spuchlakova, The Importance of Corporate Identity in Water Transportation Company. Procedia Economics and Finance, 26, 286-291 (2015)

6. C. Eun-Mi and J. Hyun-Shin, The study of Samsung Corporate Identity from Management - Philosophy and Slogan point of view. Asia-pacific Journal of Multimedia services convergent with Art, Humanities, and Sociology, 7, 1-20 (2017)

7. D. Moise and A. Cruceru, The characteristics of sales forces in relation with marketing activities carried out by the Romanian companies. Procedia - Social and Behavioral Sciences, 62, 198 - 202 (2012)

8. R. Bidin, A. Muhaimi and J. Bolong, Strategising Corporate Identity for the Perception of Corporate Image in the Selected Government-linked Companies (GLCs) in Malaysia. Procedia - Social and Behavioral Sciences, 155, 326-330 (2014)

9. A. Buhl, M. Schmidt-Keilich, V. Muster, S. Blazejewski, U. Schrader, C. Harrach, M. Schafer, E. Sussbauer. Design thinking for sustainability: Why and how design thinking can foster sustainability-oriented innovation development. Journal of Cleaner Production, 231, 1248-1257 (2019) 
10. D. Kiselakova, B. Sofrankova, M. Gombar, V. Cabinova, E. Onuferova. Competitiveness and Its Impact on Sustainability, Business Environment, and Human Development of EU (28) Countries in terms of Global Multi-Criteria Indices. Sustainability. 11 (12), 3365 (2019)

11. J. Ukko, M. Saunila, T. Rantala, J. Havukainen. Sustainable development: Implications and definition for open sustainability. Sustainable Development. 27 (3), 321-336 (2019)

12. J. Opon and M. Henry (2019). An indicator framework for quantifying the sustainability of concrete materials from the perspectives of global sustainable development. Journal of Cleaner Production. 218, 718-737 (2019)

13. C. Costache, D. Plesea, AI. Buzatu. Social sustainability and the impact in the business development. Quality - Access to Success. 20, 202-207 (2019)

14. W. Filho, C. Shiel, A. Paço, M. Mifsud, L. Ávila, L. Brandli, P. Molthan-Hill, P. Pace, U. Azeiteiro, V. Vargas, S. Caeiro. Sustainable Development Goals and sustainability teaching at universities: Falling behind or getting ahead of the pack? Journal of Cleaner Production. 232, 285-294 (2019)

15. A. Prashar. Towards sustainable development in industrial small and Medium-sized Enterprises: An energy sustainability approach. Journal of Cleaner Production. 235, 977-996 (2019)

16. S.Y. Chen. Green organizational identity: sources and consequence. Management Decision. 49 (3), 384-404 (2011)

17. WH. Song, SC, Ren, J. Yu. Bridging the gap between corporate social responsibility and new green product success: The role of green organizational identity. Business Strategy and the Environment. 28 (1), 88-97 (2019)

18. A. Krizanova, J. Majerova, K. Zvarikova. Green Marketing as a Tool of Achieving Competitive Advantage in Automotive Transport. 17th International Conference on Transport Means, Kaunas, Lithuania, (24-25 October, 20113), Transport Means Proceedings of the International Conference, 45-48 (2013)

19. K. Janoskova, J. Kliestikova. Analysis of the Impact of Selected Determinants on Brand Value. Journal of International Studies. 11 (1), 152-162 (2017)

20. K. Valaskova, J. Kliestikova, A. Krizanova, Consumer Perception of Private Label Products: An Empirical Research. Journal of Competitiveness, 10, 3, 149-163. (2018)

21. JA. Jaramillo, JWZ. Sossa, GLO. Mendoza. Barriers to sustainability for small and medium enterprises in the framework of sustainable development-Literature review. Business Strategy and the Environment. 28 (4) 512-524 (2019)

22. I.A. Zhulega, N.L. Gagulina, A.V. Samoylov, A.V. Novikov. Problems of corporate economics and sustainable development in the context of the sanction world order: Living standards and live quality. Ekonomicko-manazerske spektrum. 13 (1), 83-95 (2019)

23. A.E. Nielsen and T. Johansen. Corporate Social Responsibility and Corporate Identity: Corporate Marketing, Identity and Communication. (2009)

24. A.E. Nielsen and C. Thomsen, Investigating CSR communication in SMEs: a case study among Danish middle managers. Business Ethics: A European Review, 18 (1), 83-93 (2009) 